\title{
UMA CARACTERIZAÇÃO DOS MUNICÍPIOS SEM DECLARAÇÕES DE RECEITAS ANUAIS NA BASE FINANÇAS DO BRASIL: DADOS CONTÁBEIS DOS MUNICÍPIOS (2013-2018) ${ }^{1}$
}

\author{
Rodrigo Luis Comini Curi \\ Luís Gustavo Vieira Martins ${ }^{3}$ \\ Marco Aurélio Costa ${ }^{4}$
}

\begin{abstract}
1 INTRODUÇÃO
No âmbito da descentralização administrativa e tributária ensejada pela Constituição Federal de 1988, bem como das exigências impostas pela Lei de Responsabilidade Fiscal (LRF), Lei Complementar (LC) no 101/2000, ao equilíbrio e controle das finanças públicas, as demandas pelo acesso às informaçôes fiscais e orçamentárias dos entes da Federação se tornou progressiva (Medeiros et al., 2014). A elaboração e a implementação de políticas públicas nos municípios brasileiros podem, de fato, se tornar mais efetivas quando as informaçôes sobre a situação socioeconômica desses entes podem ser associadas ao perfil e dinâmica das suas fontes de recursos e à sua capacidade de gasto, quando estas se mostram confráveis, abrangentes e de fácil acesso.

Nesse contexto, esse trabalho tem por objetivo investigar os municípios que não possuem informações na base Finanças do Brasil: Dados Contábeis dos Municípios (Finbra), no que diz respeito às suas receitas anuais. O Finbra é um banco de dados que reúne, entre outras informaçóes, os resultados fiscais e contábeis de natureza autodeclarada pelos municípios, que devem ser encaminhados a cada exercício, e consolidados pela Secretaria do Tesouro Nacional (STN). Desde 2014, com a criação do Sistema de Informaçôes Contábeis e Fiscais do Setor Público Brasileiro (Sincofi), desenvolvido pela STN em parceria com o Serviço Federal de Processamento de Dados (Serpro), tais informaçôes passaram a ser enviadas à STN por meio eletrônico, promovendo uma alternativa às declaraçóes antes consolidadas pelos municípios em documentos físicos e disquetes, enviados à STN por meio de terceiros. ${ }^{5}$

1. DOl: http://dx.doi.org/10.38116/brua24art5.

2. Assistente de pesquisa III na Diretoria de Estudos e Políticas Regionais, Urbanas e Ambientais (Dirur) do Ipea.

3. Analista de planejamento e orçamento em exercício na Dirur/lpea; e pesquisador em políticas públicas e desenvolvimento territorial (INPuT) do Instituto Nacional de Ciência e Tecnologia (INCT).

4. Técnico de planejamento e pesquisa na Dirur/Ipea; e coordenador nacional do INPut/INCT.

5. Disponível em: <https://siconfi.tesouro.gov.br/siconfi/pages/public/conteudo/conteudo.jsf?id=21904>.
\end{abstract}


Este texto considera as Declaraçôes de Contas Anuais (DCAs) municipais referentes aos resultados de suas receitas orçamentárias (DCA-RB, anexo I-C do Manual de Contabilidade Aplicado ao Setor Público). Como o Sincofi entrou em funcionamento em 2014, recebendo informações do exercício anterior, 2013, este trabalho considera os exercícios de 2013 a 2018, uma vez que os dados de 2019 e 2020 estáo ainda em processo de consolidaçáo no momento em que este artigo é escrito. ${ }^{6}$

A base Finbra é de extrema relevância para a análise sobre as finanças municipais, uma vez que se constitui na fonte de informaçóes mais abrangente sobre esse universo. No entanto, apesar de ter sido aperfeiçoada consistentemente ao longo do tempo, ainda possui diversas imperfeiçóes, dado que algumas prefeituras ou não prestam contas anualmente à STN ou registram os dados de modo inadequado (Orair e Alencar, 2010). Nesse sentido, se fazem pertinentes alguns comentários sobre o processo de declaração das informaçôes orçamentárias pelos municípios e de constituição da base Finbra.

O Finbra corresponde à DCA, para fins de cumprimento do art. 51 da LRF, e visa dar suporte ao processo anual de consolidaçáo nacional e por esfera de governo das contas dos entes da Federação relativas ao exercício anterior (até o dia 30 de junho de cada ano), pelo governo federal. O prazo para entrega dos dados pelos municípios vai até 30 de abril de cada ano.

Conforme definido no $\$ 4^{\circ}$ do art. 48 da LRF, ${ }^{7}$ a inobservância das regras da norma de que trata do tema ${ }^{8}$ impedirá, até que a situação seja regularizada, que o ente da Federação receba transferências voluntárias e contrate operaçóes de crédito, exceto as destinadas ao refinanciamento do principal atualizado da dívida mobiliária. Esse item também compóe o Serviço Auxiliar de Informaçóes para Transferências Voluntárias (Cauc). Outra forma passível de sanção na ausência de declaraçôes municipais poderá advir caso a STN identifique indícios de descumprimento do disposto nas regras do Manual de Contabilidade Aplicada ao Setor Público (MCASP) vigente. O formato e a estrutura da DCA devem ser compatíveis com as regras estabelecidas, inclusive as relativas ao Plano de Contas Aplicado ao Setor Público (PCASP), como forma de verificação do efetivo cumprimento dos arts. 11 e 12 da Portaria STN no 634, de 19 de novembro de 2013. Com a finalidade de avaliaçáo da qualidade da informaçáo contábil, poderáo ser criados, na forma do inciso II do art.15, indicadores qualitativos obtidos da DCA relacionados à implantaçáo, na forma e prazos previstos pelo Plano de Implantação dos Procedimentos Contábeis Patrimoniais aprovado pela Portaria STN no 548, de 24 de setembro de 2015, dos procedimentos referidos nos arts. 6o e 7o $\mathrm{da}$ Portaria STN no 634, de 2013. A STN deve comunicar ao respectivo tribunal de contas e ao conselho profissional de contabilidade os fatos encontrados, o que poderá redundar em punições aos envolvidos.

Salvo as restriçôes acima apontadas, não existe nenhum mecanismo de sanção direta aos municípios, especificamente pelo fato de não declararem suas contas ao Finbra ou o fazerem com ausências ou atrasos, e a STN não se responsabiliza pelo preenchimento ou organização de informaçóes ausentes nessa base de dados. Muitos municípios que não têm previsão de

6. Os dados do Finbra para a elaboração deste artigo foram consultados em 24 de julho de 2020.

7. A obrigatoriedade quanto à publicação dos demonstrativos fiscais está disciplinada na LRF, nos arts. 52 e 54. Adicionalmente, 0 § 2ำ do art. 48 da LRF dispõe que os entes da Federação disponibilizarão suas informações e dados contábeis, orçamentários e fiscais conforme periodicidade, formato e sistema estabelecidos pelo órgão central de contabilidade da União, que é a Secretaria do Tesouro Nacional.

8. Portaria no 896, de 31 de outubro de 2017, da STN, que regulamenta a entrega das informações. 
receber transferências voluntárias ou contratar financiamentos só entregam esses dados posteriormente, apenas quando se torna estritamente necessário fazê-lo para viabilizar tais operaçóes. A partir desses espaços, é possível que a base se mostre incompleta ou enviesada para alguns municípios. Importante ressaltar que, mesmo com essas questóes, a base Finbra é de extrema importância para a análise de dados orçamentários e contábeis municipais.

Este artigo apresenta um perfil dos municípios que, a cada ano, não declararam suas receitas anuais à STN,${ }^{9}$ construído a partir de suas características populacionais, geográficas e socioeconômicas, com o objetivo de contribuir com a construção e consolidação de bases informacionais sobre as finanças municipais no Brasil. Para este trabalho, consideramos apenas os municípios que não informaram nenhuma de suas receitas ao Finbra, e que, portanto, não estão presentes na base. No entanto, é possível que municípios presentes no Finbra tenham declarado apenas parte de suas contas, tendo, portanto, ausências em contas específicas. Conforme mencionado acima, devido à sua natureza voluntária, a ausência de declaração de contas específicas pode ocorrer devido ao fato de um município náo possuir determinada receita ou mesmo possuir, porém não a ter preenchido na DCA que compóe o Finbra. Também ocorrem casos em que o município preenche a informaçáo no campo equivocado ou comete erros de digitação. Devido ao extenso e complexo trabalho de levantamento e preenchimento dessas lacunas, ${ }^{10}$ este trabalho se debruça apenas sobre os municípios que não estáo presentes na base, ou seja, que não declararam nenhuma conta à STN no âmbito da composição do Finbra. Ele se mostra importante para se ter um quadro da dimensão da ausência de informaçóes nessa fonte de dados, da representatividade das informaçôes presentes na base e das características desses municípios sem participação no Finbra.

Por fim, é importante denotar que este artigo se insere no conjunto de pesquisas da Dirur/Ipea no apoio à construção da Política Nacional de Desenvolvimento Urbano (PNDU), junto ao Ministério do Desenvolvimento Regional e outras instituiçôes. Os dados do Finbra se colocam como uma fonte de informação central para a investigação das perspectivas e desafios para o financiamento do desenvolvimento urbano, sendo utilizados para a análise do quadro de arrecadação municipal, de seu balanço entre receitas próprias e transferências, do comportamento das despesas municipais e do direcionamento de gastos para o desenvolvimento urbano.

\section{CARACTERÍSTICAS DOS MUNICÍPIOS AUSENTES DA BASE DE DECLARAÇÕES DE RECEITAS ANUAIS DO FINBRA}

Ao se considerar os 5.570 municípios existentes no Brasil entre 2013-2018, em cada ano parte deles não disponibiliza seus dados do Finbra/Sincofi de declaraçôes de receitas brutas

\footnotetext{
9. Importante notar que não necessariamente são os mesmos municípios que estão ausentes a cada ano, tendo esse número de ausentes variado entre 2013 e 2018.

10. A STN atualmente não depura esses dados ausentes ou com erros de preenchimento, e suprir as lacunas de informação demandaria uma extensa pesquisa nos 26 Tribunais de Contas Estaduais (TCEs) e até mesmo diretamente nas contas municipais, pois alguns destes sequer as entregam aos TCEs. Outra limitação para depuração reside no fato de que apenas cerca da metade dos TCEs possui bases de dados estruturadas para disponibilização e tratamento adequado das informações. Esse fato foi debatido com a STN e com a área de contas nacionais do Instituto Brasileiro de Geografia e Estatística (IBGE), que há décadas realiza a análise conjuntamente com a STN para elaboração das contas nacionais. Foi verificado, inclusive, que em muitos casos os dados dos TCEs não possuem qualidade de informação superior à do Finbra. Os dados depurados caso a caso pelo IBGE restringem-se às capitais e governos estaduais, devido à sua maior relevância.
} 
realizadas, ${ }^{11}$ cujos números são demonstrados no gráfico 1 . Apesar de não mostrar um padrão específico, para a maioria dos anos a quantidade de não informantes era menor que 150 , com exceção de 2014, em que 381 municípios não constaram na base de receitas do Finbra. ${ }^{12}$ É importante considerar que, mesmo náo tendo todos os municípios respondido ao Finbra ano a ano, essa base se mostra significativamente representativa. Em 2018, os municípios informantes representaram $98,17 \%$ da populaçáo brasileira, e, em 2017, os que responderam ao Finbra representaram $96 \%$ do produto interno bruto (PIB) do país. ${ }^{13}$

A seguir, serão apresentadas algumas características populacionais, geográficas e socioeconômicas dos municípios ausentes em cada ano, de modo a investigar o perfil municipal de não aderência às declarações anuais por meio eletrônico consolidadas na plataforma Sincofi.

GRÁFICO 1

Municípios ausentes da DCA-RB (2013-2018)

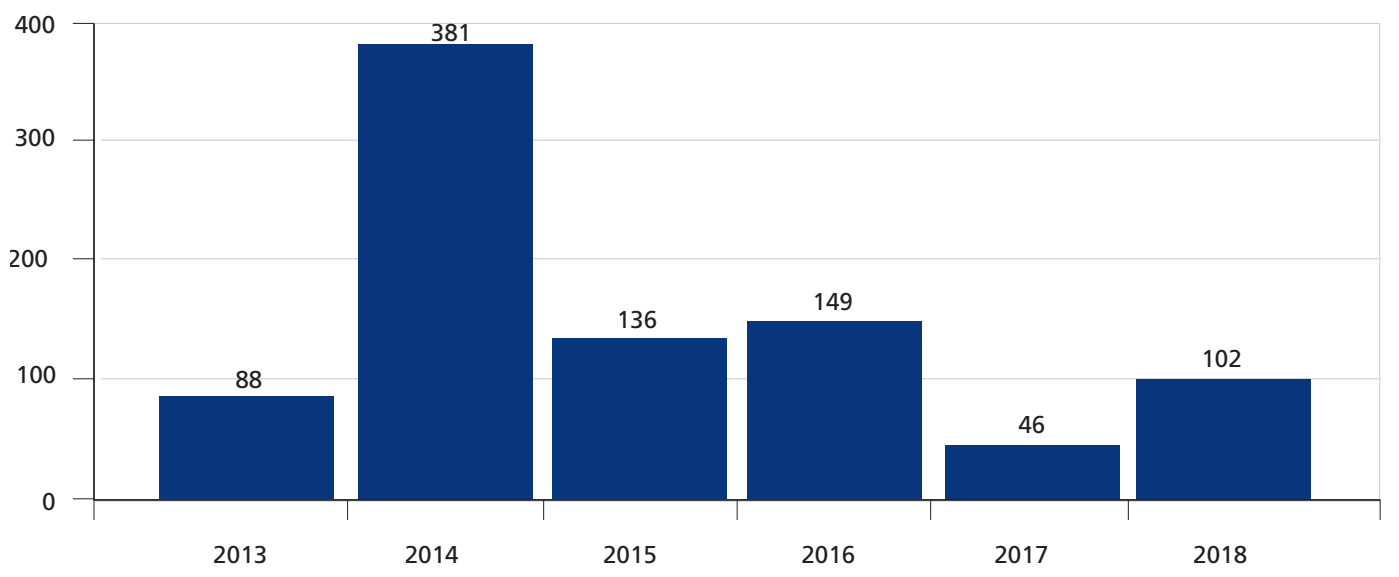

Fonte: Sincofi/STN; Finbra.

\subsection{Características populacionais dos municípios}

A tabela 1 apresenta a distribuição dos municípios em cada ano em relação a sua população total, de acordo com as estimativas populacionais dos municípios realizada pelo IBGE $^{14}$ e disponíveis no Sistema IBGE de Recuperação Automática (Sidra). Para todos os anos, a maioria dos municípios não informantes possuíam entre 5 mil e 50 mil habitantes. ${ }^{15}$

11. Este estudo considera apenas as receitas brutas declaradas pelos municípios, não incorporando a declaração de suas deduções de receita. Sendo assim, no recorte temporal adotado, apenas em 2013 existem três municípios que não possuem receitas brutas realizadas na base de receitas disponível pelo Sincofi, sendo, portanto, considerados neste texto, mas possuem algumas deduções. São eles: São Miguel de Taibu, na Paraíba; Duas Barras, no Rio de Janeiro; e Sucupira do Riachão, no Maranhão.

12. Na comparação entre municípios, sete municípios são comuns a todos os anos: Curralinho, Muaná e Santarém Novo, no Pará; Rafael Fernandes, no Rio Grande do Norte; Fernando de Noronha, em Pernambuco; Flexeiras, em Alagoas; e Aperibé, no Rio de Janeiro. Todos são municípios com população entre 3 mil e 40 mil habitantes. Brasília também não consta no Finbra, sendo tratada de forma diferente devido ao seu status de capital nacional.

13. Dados auxiliares extraídos das estimativas populacionais e do PIB municipal, realizadas pelo IBGE. Para o PIB, o ano mais recente em que os dados municipais estavam disponíveis no Sidra no período em que este texto foi escrito era de 2017. 14. Mais informações sobre as estimativas das populações dos municípios (EstimaPop) disponíveis em: <https://metadados. ibge.gov.br/consulta/estatisticos/operacoes-estatisticas/XF>.

15. Excluímos Brasília dessa e das análises subsequentes, uma vez que o Distrito Federal possui ordenamento jurídico específico, que inclui competências dos entes estaduais. 
O único município do grupo entre 300 mil e 750 mil habitantes ausente do Finbra foi Caruaru, Pernambuco, em 2014, com uma população de 342.328 habitantes nesse ano. Chamam a atenção também alguns municípios entre 100 mil e 300 mil habitantes ausentes da base considerada. Para esse grupo populacional, Altamira, no Pará, aparece como não informante em todos os anos entre 2015 e 2018.

TABELA 1

Municípios ausentes em cada ano por grupo populacional (2013-2018)

\begin{tabular}{|c|c|c|c|c|c|c|}
\hline Porte populacional & 2013 & 2014 & 2015 & 2016 & 2017 & 2018 \\
\hline Até 5 mil & 31 & 88 & 19 & 16 & 6 & 28 \\
\hline $5 \mathrm{mil} \mathrm{a} 10 \mathrm{mil}$ & 11 & 102 & 31 & 33 & 13 & 29 \\
\hline 10 mil a 20 mil & 25 & 96 & 37 & 41 & 13 & 20 \\
\hline 20 mil a 50 mil & 20 & 61 & 40 & 45 & 9 & 19 \\
\hline 50 mil a 100 mil & - & 18 & 6 & 10 & 3 & 2 \\
\hline $100 \mathrm{mil} \mathrm{a} 300 \mathrm{mil}$ & - & 14 & 2 & 3 & 1 & 3 \\
\hline 300 mil a 750 mil & - & 1 & - & - & - & - \\
\hline Acima de 750 mil & - & - & - & - & - & - \\
\hline Total & 88 & 381 & 136 & 149 & 46 & 102 \\
\hline
\end{tabular}

Fonte: Sincofi/STN; Finbra; IBGE.

Obs.: Para cada grupo populacional, os dados são inclusivos no limite inferior e exclusivos no superior.

O gráfico 2 mostra a distribuição dos municípios ausentes em cada ano, segundo a porcentagem da população residente em áreas rurais em relação ao total populacional, referentes ao censo demográfico de 2010 do IBGE. ${ }^{16}$ Para os anos de 2013, 2015 e 2016, mais da metade dos municípios náo declarantes a cada ano possuíam pelo menos $50 \%$ da sua população residente em áreas rurais, sendo a mediana em 2017 muito próxima desse resultado. Importante notar que esse resultado se refere a 2010, sendo possível que esse balanço populacional tenha mudado, especialmente para anos mais recentes, como $2017 \mathrm{e}$ 2018. No entanto, esses dados mostram que grande parte dos municípios náo informantes tem a maioria de seu contingente populacional em áreas rurais.

\section{GRÁFICO 2}

Distribuição dos municípios ausentes em 2010 (2013-2018)

(Em \% da população rural)

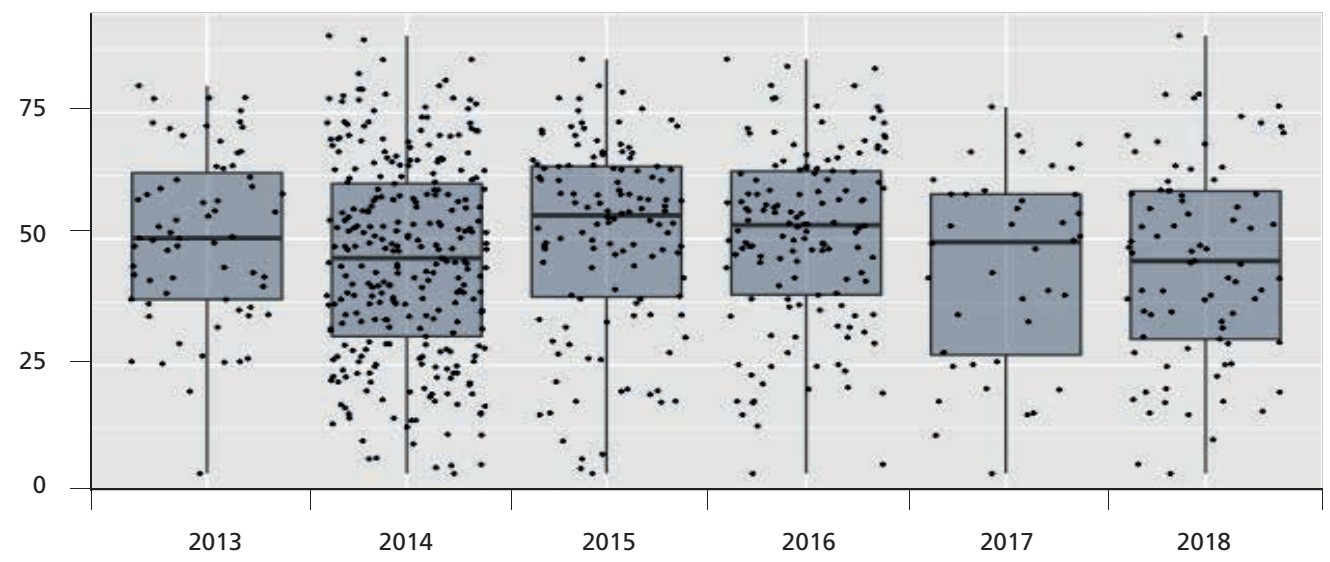

Fonte: Sincofi/STN; Finbra; Ipea.

16. Dados extraídos da plataforma Atlas da Vulnerabilidade Social, do Ipea, referente ao censo demográfico de 2010. Devido a questões de amostragem, nem todos os 5.565 municípios de 2010 foram desagregados para situaç̃es de domicílio (rural e urbano). 


\subsection{Características geográficas dos municípios}

A tabela 2 apresenta a distribuição dos municípios por região. A maioria dos anos mostrou um número maior de municípios ausentes da base na regiáo Nordeste, seguida do Norte. As regióes Centro-Oeste e Sul foram aquelas com menor número de municípios ausentes. A exceção se dá em 2014, em que o maior número de municípios se mostrou nas regiôes Sul e Sudeste, seguido do Nordeste. $\mathrm{O}$ ano de 2016 chama a atençáo pela grande diferença entre o número de municípios ausentes nas regiôes Norte e Nordeste, quando comparadas com as demais do país, todas na casa de um dígito, enquanto o Nordeste mostrou quase oitenta municípios sem adesão ao Finbra/Sincofi naquele ano.

\section{TABELA 2}

Região dos municípios ausentes (2013-2018)

\begin{tabular}{lcccccc}
\hline Região & 2013 & 2014 & 2015 & 2016 & 2017 & 2018 \\
\hline Centro-Oeste & 14 & 50 & 8 & 5 & 5 & 26 \\
Nordeste & 30 & 88 & 63 & 78 & 21 & 38 \\
Norte & 25 & 40 & 47 & 54 & 15 & 18 \\
Sudeste & 11 & 96 & 14 & 9 & 4 & 14 \\
Sul & 7 & 106 & 3 & 2 & - & 5 \\
\hline
\end{tabular}

Fonte: Sincofi/STN; Finbra.

Além da macrorregiáo desses municípios, cabe o questionamento se o município faz parte de uma região metropolitana $(\mathrm{RM})$, o que podemos entender como uma proxy para um município com maior dinâmica socioeconômica e de relaçôes com outros territórios. O gráfico 3 mostra a distribuição dos municípios ausentes ano a ano por posição em relação a uma RM brasileira, divididos em três grupos: municípios institucionalmente pertencentes a uma RM mas que não são sede, municípios que são capitais metropolitanas (sede) e outros municípios que não pertencem institucionalmente a uma RM (outros).

GRÁFICO 3

Caracterização dos municípios ausentes em relação à posição na RM (2013-2018)

2013
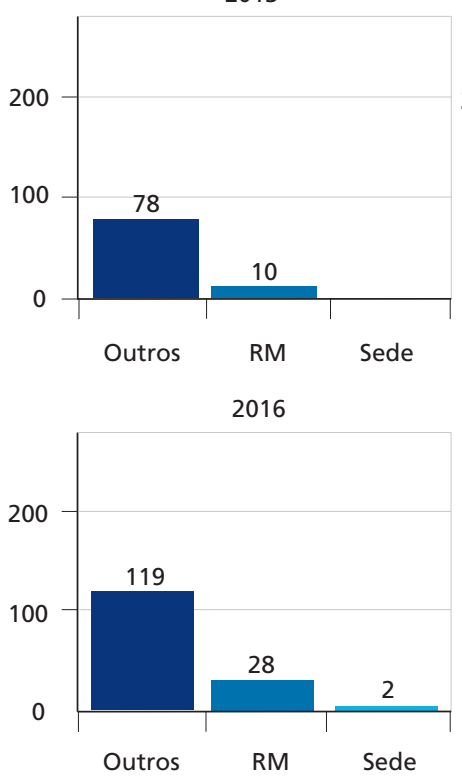

2014
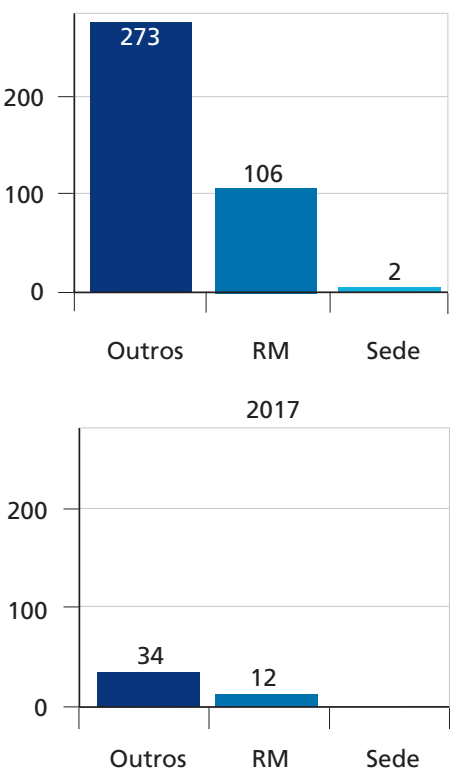

2015

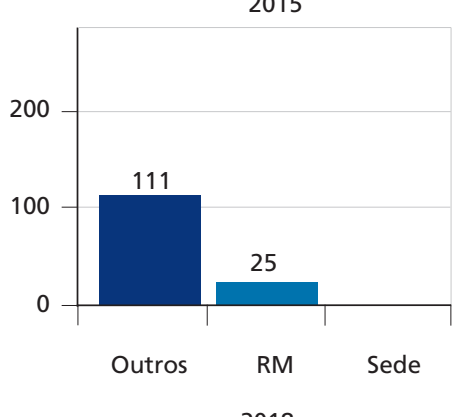

2018

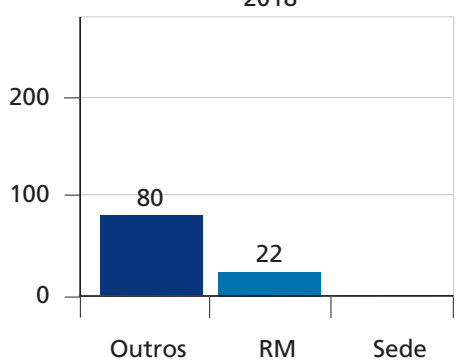

Fonte: Sincofi/STN; Finbra; Atlas da Governança Metropolitana no Brasil, disponível em: <http://brasilmetropolitano.ipea.gov.br/>. 
O gráfico mostra que, para todos os anos considerados, a maioria dos municípios que não constaram na base de receitas anuais do Finbra/Sincofi não faz parte de uma RM, sendo o balanço entre metropolitanos e não metropolitanos diferente ao longo dos anos (em 2017, esses números foram mais próximos que nos outros anos). Com exceção de 2014, em que o número de não adesóes ao Finbra foi destacadamente maior em relação aos outros anos, o maior número de municípios ausentes pertencentes à alguma RM ocorreu em 2016. Esse ano também, junto com 2014, foram os únicos em que sedes metropolitanas não se encontravam na base do Finbra. Em 2016, esses municípios foram Caracaraí, sede da RM central, em Roraima; e Itabaiana, sede da RM de Itabaiana, na Paraíba. Por sua vez, em 2014, as duas ausentes foram Patos, sede da RM de Patos, na Paraíba, e Palmeira dos Índios, sede da RM de Palmeira dos Índios, em Alagoas.

Um outro olhar com relação às características dos municípios que não aderiram ao Finbra no recorte temporal adotado se dá na sua posição na Região de Influência das Cidades (Regic), estudo realizado periodicamente pelo IBGE. Apesar de considerar também a proximidade geográfica entre os municípios, a Regic aborda diversos outros aspectos municipais, com o intuito de analisar a rede urbana brasileira e estabelecer hierarquias de centros urbanos e regióes de influência das cidades, tais como movimentos pendulares de trabalho, trocas comerciais, ocorrência de eventos culturais, entre outros. ${ }^{17}$

A tabela 3 mostra a distribuição desses municípios em relação à hierarquia dos centros urbanos da Regic, a saber: metrópoles, correspondentes aos principais centros urbanos, com ampla influência sobre o território nacional; capitais regionais, com menor alcance de influência comparadas com as metrópoles, mas com alta concentração de atividades de gestão; os centros sub-regionais, com atividades de gestão menos complexas, menor região de influência e porte populacional; centros de zona, já com menores níveis de atividades de gestão e relaçôes comerciais e de serviços baseadas na proximidade com outras regióes; e os centros locais, cidades que exercem influência restrita a seus próprios limites territoriais, podendo atrair populaçóes de outros territórios mas não sendo o seu destino principal.

TABELA 3

Distribuição dos municípios ausentes em relação à posição na Regic (2013-2018)

\begin{tabular}{lcccccc}
\hline Regic & 2013 & 2014 & 2015 & 2016 & 2017 & 2018 \\
\hline Centro local & 85 & 323 & 122 & 131 & 82 & 88 \\
Centro de zona & 1 & 28 & 6 & 5 & 1 & 7 \\
Centro sub-regional & - & 14 & 4 & - & - & - \\
Capital regional & - & 2 & - & - \\
Metrópole nacional & - & - & - & - \\
\hline
\end{tabular}

Fonte: Sincofi/STN; Finbra; IBGE.

A tabela aponta que em todos os anos a maioria dos municípios ausentes correspondia a centros locais na classificaçáo hierárquica da Regic, seguidos de centros de zona e centros sub-regionais. $\mathrm{O}$ ano de 2014 foi o único em que se registrou a ausência de capitais regionais no Finbra, apenas duas: Araguaína, Tocantins, e Caruaru, Pernambuco.

17. Para mais informações sobre a Regic, ver IBGE (2020). 


\subsection{Características socioeconômicas}

O terceiro bloco de características municipais levanta alguns aspectos socioeconômicos dos municípios. A tabela 4 apresenta uma classificação municipal com base em grupos de renda per capita, a partir dos dados do censo demográfico de 2010. A partir dos resultados apresentados, percebe-se uma concentração de municípios nas faixas de renda per capita média de $\mathrm{R} \$ 100,00$ a $\mathrm{R} \$ 500,00$, abaixo da média do Brasil no período em que o censo foi realizado, de $\mathrm{R} \$ 793,87$. Tanto em 2015 quanto em 2016 apenas um município se encontrava com renda per capita menor de R \$100,00, a saber, o município de Marajá do Sena, no Maranhão. À exceção de 2014, poucos municípios apresentaram renda per capita acima de $\mathrm{R} \$ 500,00$.

TABELA 4

Renda per capita dos municípios ausentes em $2010^{1}$ (2013-2018)

\begin{tabular}{|c|c|c|c|c|c|c|}
\hline Renda per capita & 2013 & 2014 & 2015 & 2016 & 2017 & 2018 \\
\hline Até $\mathrm{R} \$ 100$ & - & - & 1 & 1 & - & - \\
\hline$R \$ 100$ a $R \$ 200$ & 15 & 15 & 26 & 36 & 6 & 11 \\
\hline$R \$ 200$ a $R \$ 300$ & 31 & 85 & 59 & 67 & 23 & 36 \\
\hline$R \$ 300$ a $R \$ 500$ & 22 & 95 & 35 & 31 & 9 & 23 \\
\hline$R \$ 500$ a $R \$ 1.000$ & 17 & 176 & 13 & 12 & 6 & 29 \\
\hline$R \$ 1.000$ a $R \$ 1.500$ & 2 & 9 & 1 & 1 & 1 & 2 \\
\hline Acima de $R \$ 1.500$ & - & - & - & - & - & - \\
\hline
\end{tabular}

Fonte: Sincofi/STN; Finbra; Ipea.

Nota: ${ }^{1}$ Em reais de agosto de 2010.

Em complementação à análise da renda per capita, o gráfico 4 apresenta a distribuição dos municípios pelo valor do Índice de Vulnerabilidade Social (IVS), em 2010. O IVS é um índice sintético desenvolvido pelo Ipea com o intuito de identificar e mapear no território brasileiro situaçôes de vulnerabilidade social. ${ }^{18}$ Ele é composto por dezesseis indicadores divididos em três dimensóes - capital humano, renda e trabalho e infraestrutura urbana. Seus valores variam de 0 a 1 , divididos em cinco faixas de vulnerabilidade: 0 a 0,200 (muito baixa), 0,201 a 0,300 (baixa), 0,301 a 0,400 (média), 0,401 a 0,500 (alta), e 0,500 a 1 (muito alta).

Pelo gráfico, novamente com exceção de 2014, percebe-se que em todos os anos a maioria dos municípios mostrava um IVS nas faixas de alta e muito alta vulnerabilidade social, sendo o ano de 2016 com menor variabilidade nos valores municipais. Junto com 2015, foram os dois anos em que pelo menos metade dos municípios em cada ano mostraram um IVS acima de 0,500, caracterizando situaçôes de muito alta vulnerabilidade social. Por sua vez, talvez por ter um grupo maior de municípios que não aderiram ao Finbra, 2014 mostrou uma maior concentração de seus municípios ausentes em faixas mais baixas do IVS, abaixo de 0,300 .

18. O IVS identifica situações de vulnerabilidade social entendidas como a falta ou insuficiência de ativos essenciais para 0 bem-estar de um individuo ou grupo populacional, em que o acesso a tais ativos não depende somente do indivíduo, mas é também responsabilidade do Estado ofertá-lo. Para mais informações sobre o IVS, ver Costa et al. (2018). 
GRÁFICO 4

IVS dos municípios ausentes em 2010 (2013-2018)

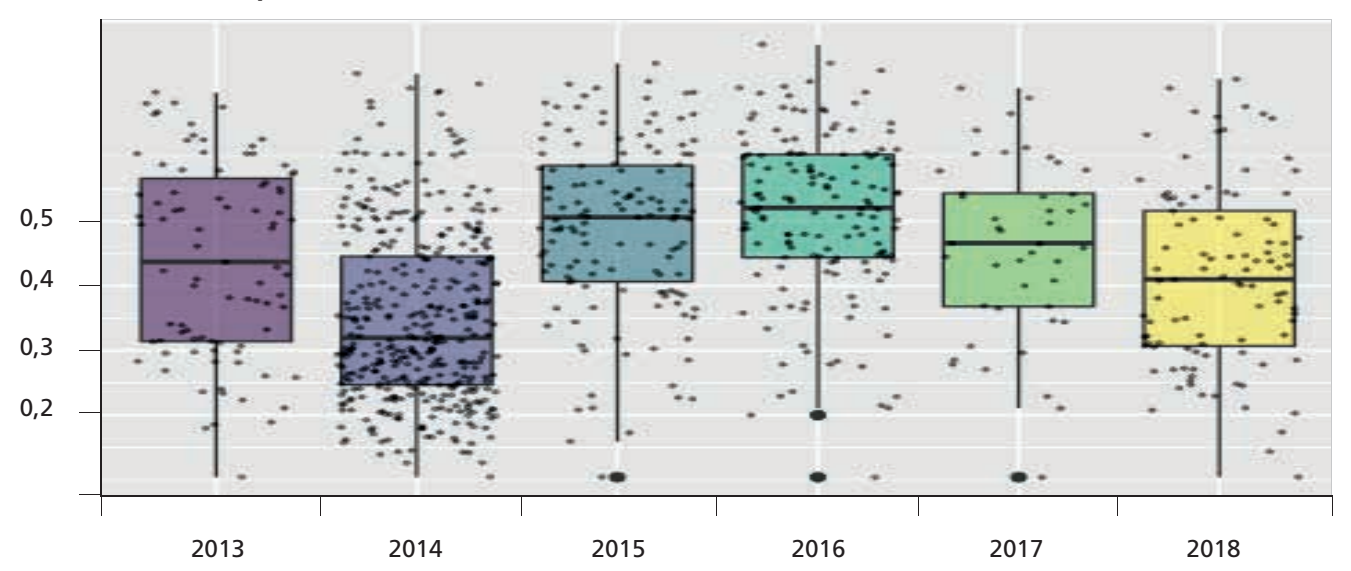

Fonte: Sincofi/STN; Finbra; Ipea.

Por fim, o gráfico 5 mostra a distribuição dos municípios ausentes em cada ano pelo valor do Índice de Desenvolvimento Humano Municipal (IDHM), uma versão do Índice de Desenvolvimento Humano (IDH) desenvolvida pelo Ipea, Programa das Naçóes Unidas para o Desenvolvimento (Pnud) Brasil e Fundação João Pinheiro (FJP), adaptada à realidade brasileira. Esse índice sintético busca identificar o nível de desenvolvimento humano no território nacional, a partir de uma estrutura baseada em sete indicadores divididos em três dimensôes: longevidade, educação e renda. Também é um índice que varia de 0 a 1 , porém, de forma oposta ao IVS: quanto mais próximo o IDHM for de 1, maior seria a indicação de desenvolvimento humano no território. O IDHM é também dividido em cinco faixas: 0 a 0,499 (muito baixo), 0,500 a 0,599 (baixo), 0,600 a 0,699 (médio), 0,700 a 0,799 (alto) e 0,800 a 1 (muito alto).

Os anos de 2013, 2018 e especialmente 2014 mostraram uma mediana mais elevada em relação a 2015, 2016 e 2017, com mais da metade dos municípios com IDHM acima de 0,600 (médio desenvolvimento humano). Os anos de 2013, 2017 e 2018 mostraram uma maior dispersão no valor do IDHM para seus respectivos municípios, diferentemente de 2015 e 2016, em que há uma concentração maior dos valores municipais em faixas mais baixas, abaixo do médio IDHM.

\section{GRÁFICO 5}

IDHM dos municípios ausentes em 2010 (2013-2018)

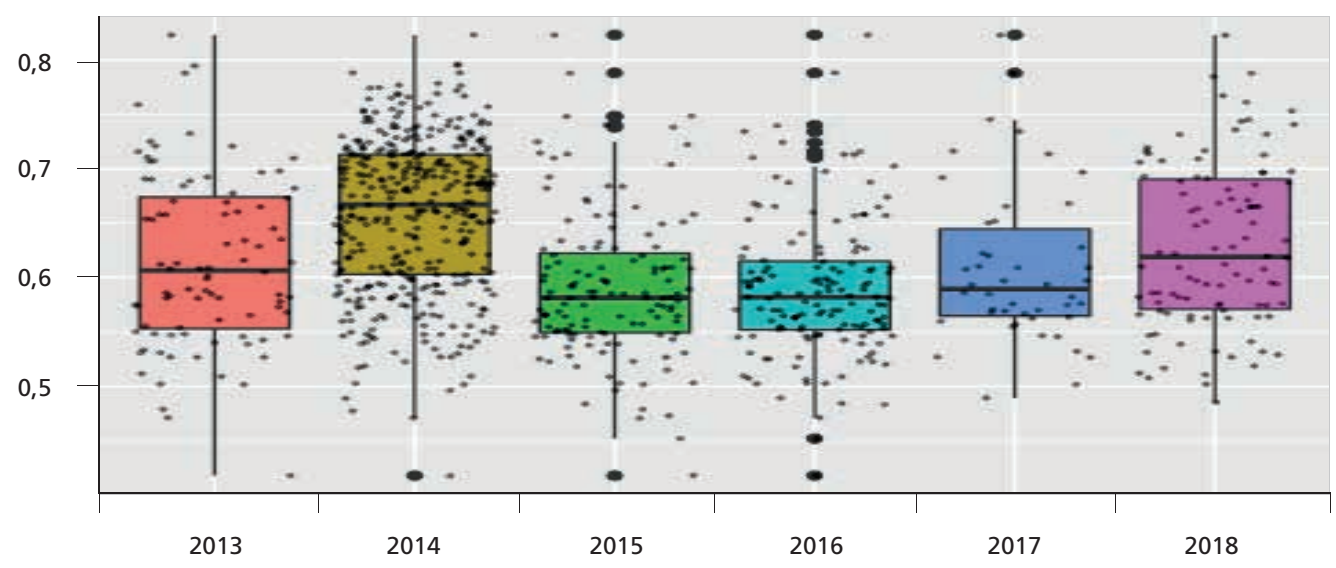

Fonte: Sincofi/STN; Finbra; Ipea. 


\section{CONSIDERAÇÕES FINAIS}

Este breve artigo procurou identificar algumas características populacionais, geográficas e socioeconômicas dos municípios que não estão presentes na base de autodeclaração do Finbra, disponível na plataforma Sincofi/STN, no intuito de contribuir para o entendimento sobre a disponibilidade de dados fiscais e orçamentários dos municípios e para as futuras construçóes e consolidaçóes de novas bases, ao caracterizar os municípios que náo aderiram à essa base sintética de dados Finbra.

Pode-se observar que o número de municípios náo informantes variou entre $0,8 \% \mathrm{e}$ $6,8 \%$ do total do país, o que aponta para uma alta adesão dos entes municipais ao Finbra. Entre os não informantes, predominam municípios de menor contingente populacional e menor grau de urbanização, em especial das regióes Nordeste e Norte do país, o que deve ser cotejado pelo número de municípios em cada uma dessas macrorregiôes.

Observou-se, também, um amplo predomínio de municípios não inseridos em regiôes metropolitanas e que exercem a posição de centro local na rede urbana brasileira, abrigando, na maior parte das vezes, uma populaçáo de rendimentos mais baixos e índices socioeconômicos menos favoráveis.

Este levantamento, que se insere na pesquisa de apoio à construção da Política Nacional de Desenvolvimento Urbano (PNDU), reforça a importância do acesso a dados e informaçóes sobre as finanças municipais e ratifica a pertinência das informaçóes disponibilizadas pela plataforma Sincofi/STN.

\section{REFERÊNCIAS}

COSTA, M. A. et al. Vulnerabilidade social no Brasil: conceitos, métodos e primeiros resultados para municípios e regiôes metropolitanas brasileiras. Brasília: Ipea, 2018. (Texto para Discussão, n. 2364).

IBGE - INSTITUTO BRASILEIRO DE GEOGRAFIA E ESTATÍSTICA. Regióes de Influência das Cidades 2018. Rio de Janeiro: IBGE, 2020.

MEDEIROS, K. R. de et al. Bases de dados orçamentários e qualidade da informação: uma avaliação do Finanças do Brasil (Finbra) e do Sistema de Informaçôes sobre Orçamentos Públicos em Saúde (Siops). Revista de Administraçáo Pública, v. 48, n. 5, p. 1113-1133, 1 set. 2014.

ORAIR, R. C.; ALENCAR, A. A. Esforço fiscal dos municípios: indicadores de condicionalidade para o sistema de transferências intergovernamentais. Brasília: Esaf, 2010. 